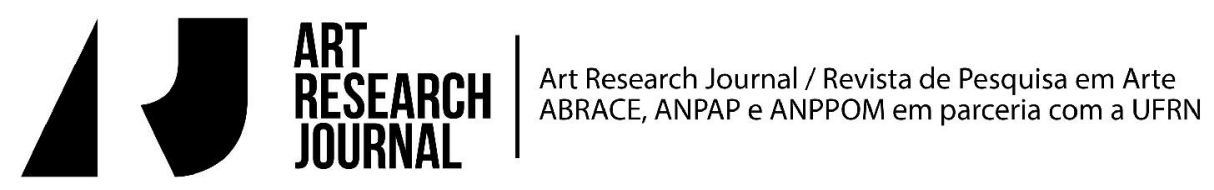

\section{Experiências de performatividade na cena brasileira contemporânea}

Sílvia Fernandes

PPGAC-ECA/USP

Em relação à pesquisa em ciências humanas, e na contramão das opiniões correntes, Giorgio Agamben afirma que a reflexão sobre o método não precede a prática, mas a sucede (Agamben, 2008, p. 7). Os procedimentos de investigação em geral são definidos a posteriori, como justificativas do longo e contínuo hábito de pesquisar. A observação é recuperada para justificar algumas trajetórias de pesquisa em artes cênicas que tenho acompanhado no decorrer dos anos de investigação na área e, em certo sentido, refletem meu próprio percurso. Faz parte desse reconhecimento metodológico a posteriori a descoberta recente de que vários pesquisadores de teatro contemporâneo brasileiro têm trabalhado com pressupostos da crítica genética, dos quais, até pouco tempo, não se tinha consciência precisa.

É evidente que as metodologias nunca são puras e parecem nutrir-se, ao menos no caso das artes cênicas, de um inevitável hibridismo, decorrente da natureza fugidia do objeto. O fato acentua-se no teatro contemporâneo por tratar-se de uma arte performativa da presença, da efemeridade e da desconstrução gestada no próprio processo criativo da cena em constante work in progress.

Voltando a Agamben, não é possível dar conta da elaborada reflexão que desenvolve em seu livro sobre o método, Signatura rerum. Mas, no interesse deste argumento, é importante frisar que o filósofo defende o postulado de que a teoria só pode ser exposta, com legitimidade, sob a forma de interpretação. O que significa que o método nunca está completamente separado do contexto em que opera e, mais ainda, que não existem métodos válidos em qualquer domínio, da mesma forma que não há lógica dissociada dos objetos. No entanto, a prudência arqueológica recomenda ao pesquisador recuar sobre os passos dos criadores em seu esforço de análise. 
Em proveito da abordagem que se faz aqui, pode-se especular em que medida a arqueologia de Agamben tem afinidade com certos procedimentos da crítica genética. Talvez o grande diferencial da metodologia, recentemente aplicada à cena teatral, seja a preocupação em aliar a análise teórica aos processos criativos e à prática do teatro, fazendo desse trânsito o foco de atuação. Enquanto a semiologia teatral, de larga influência nos anos 1970 e 1980, com representantes da estatura de Patrice Pavis, Anne Ubersfeld e Marco de Marinis, dedicava-se à definição dos signos espetaculares, debruçando-se sobre a passagem do texto à cena e centrando-se na compreensão do teatro como escritura do espetáculo, a crítica genética dava seus primeiros passos no território dos processos de criação teatral. Foi o período em que a pesquisadora Josette Féral iniciou investigações focadas nos procedimentos criativos do Théâtre du Soleil, por exemplo, prenunciando o que seria um dos marcos preferenciais de análise do teatro contemporâneo. Naquele momento, a ensaísta aproximava-se da pesquisa genética, priorizando as etapas que precedem a apresentação de um trabalho teatral e prenunciando uma prática analítica corrente nos estudos contemporâneos. O acompanhamento, a observação e o estudo do processo, a compreensão do percurso do encenador, dos atores e da equipe de criação, a investigação dos rastros da feitura artística do espetáculo constituem, hoje, procedimentos imprescindíveis ao esclarecimento daquilo que se apresenta no palco ou fora dele. Mas foi nessa etapa que o trabalho em processo, inacabado, passou a ser levado em conta no mesmo nível que as questões ligadas à representação.

A crítica genética aplicada ao teatro principia, efetivamente, nos anos de 1990, depois de uma longa pré-história de edições comentadas de grandes paradigmas da dramaturgia ocidental, que em geral reproduzem e analisam os esboços sucessivos das versões das obras. Mas os procedimentos que mais se aproximam da abordagem específica da própria cena ganham força apenas no final do século XX, com os estudos pioneiros de Almuth Grésillon e os seminários internacionais organizados para a discussão dos procedimentos genéticos no teatro, que divulgam a metodologia (Grésillon, Mervant-Roux, Budor, p. 2010).

Precedendo essas iniciativas, destacam-se os estudos de Féral, já mencionados, as edições comentadas de cadernos de direção de encenadores e os vários volumes da série Voies de la création théâtrale, editados pelo CNRS a partir de 
1972, com reconstituição de espetáculos e processos criativos de encenadores da importância de Peter Brook, Giorgio Strehler, Tadeusz Kantor, Robert Wilson, Patrice Chéreau e Claude Régy, entre outros.

No teatro brasileiro, com raras exceções, a aproximação dos pesquisadores de teatro com a metodologia da crítica genética deu-se mais como fonte de inspiração e menos como constituição rigorosa de dossiês genéticos a partir de testemunhos e documentos. Na maioria dos casos, o que se retém é a iniciativa de derrubar as barreiras que separam a análise do espetáculo do estudo dos processos de criação. Nesse sentido, é possível associar a metodologia às diversas documentações sobre processos criativos produzidas pelo IDART, atualmente Divisão de Pesquisas do Centro Cultural São Paulo, às publicações sobre encenadores, como as de Sebastião Milaré sobre Antunes Filho e, mais recentemente, aos estudos de atores e diretores sobre o próprio trabalho, como os de Miriam Rinaldi e Antonio Araújo dedicados ao Teatro da Vertigem, de Leonardo Moreira referido à Companhia Hiato e de Ivam Cabral sobre o grupo Os Satyros, para citar apenas os exemplos mais próximos. O traço comum desses trabalhos é o privilégio dos processos de criação e o desenvolvimento de reflexões a partir da etnografia dos ensaios. A partir da leitura desses estudos, é possível constatar que a observação genética das etapas de criação por atores, encenadores e dramaturgistas é um meio eficaz de esclarecimento da contaminação entre diversas práticas de criação da cena, bastante comum no teatro brasileiro contemporâneo, especialmente aquele produzido em processo que se denomina colaborativo, próximo do devising theatre praticado por coletivos internacionais. Por meio do procedimento, é possível verificar de que modo o espaço, a luz, a atuação e a música associam-se para a construção de uma dramaturgia cênica e textual coletiva, mais ou menos estável, como acontece nos trabalhos coletivos dos grupos de teatro. Além da observação e da notação de ensaios, documentos de criação como manuscritos dos atores, cadernos de direção, esboços espaciais de cenógrafos e iluminadores auxiliam o mapeamento dos estágios do trabalho em processo. As gravações em vídeo, agora realizadas pelos próprios artistas, são outro modo privilegiado de indicação dos diversos passos da criação teatral.

A despeito do mergulho na prática do teatro e da experiência de partilha de processos com artistas de diversas extrações, a pesquisa genética nunca relegou 
a segundo plano as preocupações teóricas. Pelo contrário, a vivência dos ensaios levou diversos pesquisadores a prospectar, com maior acuidade, os conceitos que se adequavam aos percursos artísticos que testemunhavam. Além disso, a aproximação entre teoria e prática do teatro auxiliava não apenas pesquisadores e teóricos, mas os próprios artistas no exercício da criação. Atualmente é possível constatar que o ensaio teórico e os estudos de crítica genética são estratégias diferenciais de investigação das muitas vias de acesso ao fenômeno teatral e reafirmam a necessidade de refletir sobre o teatro a partir das práticas da cena. Para concluir essas observações, proponho as noções de performatividade e teatro performativo como chaves conceituais de abertura de novos ângulos de visão dos processos construtivos da cena híbrida do final do século XX e início do XXI.

\section{Performatividade}

O conceito de performatividade é trabalhado prioritariamente no campo de estudos da performance, que se consolidou nos Estados Unidos nos anos 1970 e 1980, especialmente com a equipe liderada por Richard Schechner, da Universidade de Nova York. A nova disciplina considera o teatro e a arte da performance como um foco de análise entre outros, delimitando seu campo de estudo de modo bastante ampliado. Para Schechner, performance é uma ação que pode ser explorada em diferentes a domínios, incluindo práticas artísticas, rituais, atividades esportivas, comportamentos cotidianos, modos de engajamento social e até mesmo demonstrações de excelência em variados setores de atuação (Schechner, 2006). Não é possível tratar aqui as inúmeras abordagens de performatividade que o ensaísta desenvolve. Para este argumento, interessa apenas reter a afirmação de que a performance nunca é um objeto ou uma obra acabada, mas sempre um processo, por estar ligada ao domínio do fazer e ao princípio da ação. ${ }^{1}$ Quanto à performatividade, seria ao mesmo tempo uma ferramenta teórica e um ponto de vista analítico, já que toda construção da realidade social tem potencial performativo (Schechner, 2010, p. 123-127).

\footnotetext{
${ }^{1}$ Se levada a efeito a definição de Schecher, pode-se incluir na performance todos os domínios da vida social, já que performar é o resultado das ações de ser (being), comportar-se (behave), fazer (doing) e mostrar o fazer (showing doing). As performances são feitas de comportamentos representados (twice behaved), de comportamentos restaurados (restored behavior) e ações (performed actions) que as pessoas treinam executar, praticam e repetem, observa o autor na apresentação do livro Performance studies. An introduction. New York and London: Routledge, 2006.
} 
No interesse desta abordagem, são mais produtivos os estudos ligados à arte da performance, especialmente quando enfatizam a presença de diversos traços performativos na linguagem do teatro contemporâneo. É o que defende a teórica alemã Érika Fischer-Lichte, ao considerar a performance uma extensão natural do campo do teatro, e não um novo paradigma, como quer Schechner. Seguindo a linha européia de abordagem do tema, focaliza suas análises no trabalho de encenadores e performers como Frank Castorf, Einar Schleef, Romeu Castelucci, Marina Abramovich e Christoph Schlingensief, para afirmar que a performance e o teatro contemporâneo são processos e não obras acabadas.

Para a Fischer-Lichte, a partir do desvio performativo que sofreu por volta dos anos 1960, o teatro não pode mais ser concebido como representação de um mundo ficcional que o público deve observar, interpretar e compreender. A participação do espectador na experiência performativa provoca uma gama tão ampla de sensações que transcende a possibilidade e o esforço de interpretação e produção de significado, não podendo ser superada nem resolvida pela reflexão. Nesse caso, entender as ações do artista é menos importante que experimentá-las, fazendo a travessia do evento proposto, que envolve os participantes em atmosfera compartilhada e espaço comum, gerando uma experiência para além do simbólico. O resultado é uma afetação física imediata que, para a ensaísta, causa uma "infecção emocional" no espectador (Fischer-Lichte, 2008, p. 36).

Josette Féral concorda com Fichter-Lichte quando apresenta a performance como força dinâmica cujo principal objetivo é desfazer as competências do teatro, que tende a inscrever o palco numa semiologia específica e normativa (Féral, 1985, p. 125-140). Enquanto o segundo é caracterizado por estrutura narrativa e representacional, manejando códigos cuja finalidade é realizar determinada inscrição simbólica do assunto, a primeira é a expressão de fluxos de desejo que tem por função desconstruir o que se formatou. Ainda que confronte os dois conceitos, percebe-se que uma das principais intenções do estudo de Féral é considerar a teatralidade a resultante de um jogo de forças entre duas realidades em oposição: as estruturas simbólicas específicas do teatro e os fluxos energéticos - gestuais, vocais, libidinais - que se atualizam na performance e implicam criações em processo, inconclusas, geradoras de lugares instáveis de manifestação cênica. Por recusar a adoção de códigos rígidos, como a definição precisa da personagem e a interpretação de um texto, o performer 
apresenta-se ao espectador como um sujeito "desejante", que em geral se expressa em movimentos autobiográficos e tenta escapar à representação e à organização simbólica que domina o fenômeno teatral, lutando por definir suas condições de expressão a partir de redes de impulso.

Em texto posterior, a ensaísta atenua a oposição estabelecida nesse ensaio inicial, sustentando que a performatividade é um dos elementos da teatralidade e todo espetáculo é uma relação recíproca entre ambos. Enquanto a performatividade é responsável por aquilo que torna uma performance única a cada apresentação, a teatralidade é o que a faz reconhecível e significativa dentro de um quadro de referências e códigos (Féral, 2000, p. 3-12). O conceito de "teatro performativo" é decorrência natural dessas conclusões da ensaísta. Discordando de Hans-Thies Lehmann a respeito do termo pós-dramático, que julga excessivamente genérico e pouco efetivo, acredita que as experiências mais radicais do teatro contemporâneo são resultado da intensa contaminação entre procedimentos da teatralidade e da performance (Féral, 2011, p. 28-35).

A despeito da discordância com Lehmann, é preciso notar que o teórico já havia observado a emergência de um campo de fronteira entre a performance e o teatro, à medida que este se aproxima cada vez mais de um "acontecimento e dos gestos de auto-representação do artista performático" (Lehmann, 2007, p. 223). É exatamente o que Féral ressalta quando afirma que o teatro contemporâneo beneficiou-se amplamente de algumas conquistas da arte da performance. A principal delas é deslocar a ênfase para a realização da própria ação, e não sobre seu valor de representação. Segundo a ensaísta, essa mutação é responsável por uma ruptura epistemológica de tal ordem que é necessário adotar a expressão teatro performativo para qualificá-la.

\section{Teatros performativos, teatros processuais}

O interesse maior deste argumento é destacar o caráter processual dos teatros performativos. Talvez a vertente mais constante desse fenômeno, especialmente no caso de alguns grupos brasileiros, seja a fuga à formalização e a recusa à criação de uma obra teatral acabada. É possível constatar que uma parcela considerável das práticas coletivas de teatro não visa apenas à criação de uma peça, ou do que se poderia considerar um produto comercializável no mercado de arte. Especialmente quando optam pelo trabalho colaborativo, esses coletivos 
são reconhecidos pelo envolvimento em longos processos de pesquisa que, ainda que visem, em última instância, à construção de um texto e um espetáculo, parecem distender-se na produção de uma série de eventos pontuais.

Nessa via, o trabalho de alguns grupos escapa do domínio relativamente seguro da "obra" acabada, para invadir territórios de natureza política, antropológica, ética e religiosa por meio de pesquisas de campo que, aparentemente, deixam em segundo plano tanto as investigações de linguagem quanto a militância explícita. Na verdade, os próprios processos desdobram-se em mecanismos recidivos de intervenção direta na realidade e funcionam como micro-criações dentro de um projeto maior de trabalho. Essas intervenções operam um desvio no que se considera a mais genuína intenção da criação teatral - a produção de uma dramaturgia e de um espetáculo - e sinalizam a multiplicação de práticas criativas pouco ortodoxas, cuja potência de envolvimento no território da experiência social tende a superar a força da experimentação estética.

Em texto recente, Jean-Claude Bernardet observa movimento semelhante no cinema e nas artes plásticas, que associa aos procedimentos da crítica genética em seu empenho de compreender o itinerário das produções. Nessa visada, as etapas de elaboração da obra não constituem os momentos de um processo que antecede um objetivo final ou uma mera preparação que deve necessariamente ser superada por ela. Bernardet constata que nas obras que the inspiram as reflexões, tendencialmente não há obra. Ou então, a obra é outra coisa. Não é o resultado de um processo de elaboração superado por uma finalização, mas é o próprio processo de criação. O crítico vê nesse movimento processual uma atitude de resistência à obra definitiva e significativa (Bernardet, 2006).

Para o filósofo francês Jacques Rancière, a dimensão política dos coletivos se evidencia em práticas processuais como essas, em que modos de discurso misturamse a formas de vida e em que cabe aos artistas criar condições para que uma experiência comunitária possa exteriorizar-se, atuando de modo a tornar pública determinada realidade política, cultural e econômica. Rancière considera os artistas coletivos "relacionais", por desenharem esteticamente as figuras da comunidade, ou melhor, recomporem não apenas a paisagem do visível, mas favorecerem sua evidenciação. E conclui que essas práticas artístico-sociais não são a simples ficcionalização do real, pois encontram seu conteúdo de verdade na mescla entre a "razão dos fatos" e a "razão da ficção" (Rancière, 2005, p. 52-54). 
Um bom exemplo são os coletivos que organizam seus trabalhos por meio de exaustivas pesquisas de campo dedicadas à coleta de depoimentos dos mais diversos cidadãos, de viagens exploratórias a bairros de periferia das grandes metrópoles brasileiras, de convívio em zonas urbanas de tráfico, criminalidade e prostituição, de ocupação teatral de albergues de moradores de rua, hospitais psiquiátricos e prisões, da prática de oficinas, debates e ensaios públicos abertos à opinião dos espectadores e, principalmente, de processos colaborativos altamente socializados, que fazem questão de incluir interlocutores tradicionalmente alijados da criação teatral e buscam uma aproximação com o espectador não restrita ao momento de apresentação do espetáculo.

Daí a complexidade do coro dissonante que resulta dos trabalhos desses grupos, formada pela sobreposição de vozes, saberes e culturas marginais, em que se explicita uma fragmentação de enunciação que funciona como mimese exata da fratura social brasileira. Casos exemplares desse tipo de processo são as experiências de $B R 3$ e Bom Retiro 958 metros, últimos trabalhos do Teatro da Vertigem.

Não por acaso, o coletivo mencionado busca espaços públicos contaminados de alta carga política e simbólica para suas apresentações, além de definir um desvio geográfico de interesses e recusar-se a funcionar em circuitos fechados de produção e recepção teatral. Em seus trabalhos, o que aparece em primeiro plano é a vontade explícita de contaminação com a realidade social mais brutal, em geral explorada em um confronto corpo a corpo com o outro, o diferente, o excluído, o estigmatizado.

Na maioria das vezes, o espetáculo que resulta dessas longas trajetórias de pesquisa não dá conta do intrincado percurso social e artístico que o precedeu. Um bom exemplo é $B R-3$, fruto de um processo de mais de dois anos, que envolveu criadores de várias áreas e foi apresentado em curta temporada de dois meses no leito do rio Tietê, em São Paulo, em 2006. O caráter processual e inacabado do trabalho é um dos índices de uma mudança radical de foco, do produto para o processo, do espetáculo teatral para travessias performativas, que se distanciam das formalizações canonizadas pela tradição crítica, para dar vazão a uma performatividade extrínseca e híbrida. Não se trata, evidentemente, de um repúdio às formas narrativas, mas da projeção de uma "estética da imperfeição", que se contrapõe às imagens bem acabadas e sedutoras postas em 
circulação na "sociedade do espetáculo", ou mesmo de um "retorno do rejeitado que não se submete ao beneficiamento da montagem" (Bernardet, 2006).

Talvez por isso os trabalhos do Teatro da Vertigem possam ser considerados teatros processuais, gestados na imperfeição, que se dedicam à investigação de questões urgentes das metrópoles brasileiras. No princípio do novo milênio, a experimentação coletiva em espaços públicos radicalizou-se na opção por travessias fluviais e urbanas, realizadas no rio Tietê e em um bairro central de São Paulo. A escolha aprofunda o movimento de jornadas espaciais que, desde o princípio, define a dramaturgia cênica do grupo. Mas nos espetáculos anteriores, que compunham a Trilogia Bíblica, os ambientes fechados de uma igreja, de um hospital e de um presídio de certa forma restringiam os trajetos performativos. Nos trabalhos estreados em 2006 e 2012, o processo de expansão da cena para o leito e as margens de um rio, em $B R 3$, ou para os corredores de um shopping center, as vias de circulação urbana, as fachadas e as marquises de edifícios e as ruínas de um teatro abandonado, em Bom Retiro 958 metros, radicalizou a relação íntima entre o núcleo temático e a experiência imersiva a que o espectador é submetido, sensorial e corporalmente. O resultado é que o centro de força desloca-se para uma dramaturgia que se constrói na fricção aguda da cena performativa com o ambiente implicado na travessia.

Como já acontecera em BR3, no caso de Bom Retiro o deslocamento pelas ruas noturnas de um bairro deserto e pelos desvãos de um teatro em ruínas é uma experiência-limite para o espectador, como fora, seis anos antes, navegar por três horas em um rio-esgoto como o Tietê. De qualquer forma, na água ou na terra, atores e espectadores entregam-se a uma experiência processual. Percebe-se que a intenção desse convite à caminhada e ao "desgarramento" é potencializar o experimento da catástrofe social por meio de sua vivência real no rio morto ou no bairro que mata sua história para transformar-se em retiro bom da moda kitsch, alegorizada no modesto Shopping Center, paraíso da formamercadoria e da exploração do trabalho de imigrantes ilegais.

Em parte, o convívio intenso que se conquista na cena-travessia das ruas e dos espaços públicos do Bom Retiro decorre da prática de derivas, de inspiração situacionista, usadas como dispositivo de intervenção urbana. ${ }^{2}$ Durante o processo criativo, as perambulações

2 Em documento publicado na fundação da Internacional Situacionista (IS), seus membros defendem as derivas como práticas de psicogeografia, afirmando que as perambulações ao acaso 
ao acaso em que os criadores se lançaram foi um modo privilegiado de interação com o bairro. De certa forma, elas se repetem na jornada performativa, em que as marcas do processo evidenciam-se na construção de um campo expandido de experiência, vivência e imersão no espaço.

As derivas na região central de São Paulo ligam-se à intenção de experimentar, no próprio território urbano, as questões mais candentes que mobiliza, neste caso o problema da imigração. A encenação associa a mão de obra imigrante das confecções e do comércio de roupas, característico do bairro, às formas atuais de exploração - os serviços e ocupações flexíveis que dão corpo à lógica estrutural de precarização do trabalho. As subcontratações e as atividades informais definem a situação da maioria dos trabalhadores do Bom Retiro, forçados a permanecer em zonas incertas de emprego, entre ocupação e desocupação (Palamin, 2012).

Replicando essa zona de incerteza, o roteiro-percurso movimenta a trama cênica por meio de ocupações e desocupações de espaço, com o auxílio de coreografias, movimentos corporais, sons, luzes e ritmos, numa trajetória que permite a convivência entre teatralidade e performatividade no mesmo fluxo. A poética da caminhada principia nos corredores de um Shopping Center, continua na travessia noturna de algumas ruas do bairro, desemboca no teatro em ruínas e volta à rua para fechar o ciclo diante de uma caçamba de entulhos.

No centro de compras, a encenação sublinha os fetiches da mercadoria em um roteiro de tensões entre a teatralidade do mundo do consumo e a performatividade da cidade real. Portões fecham-se para erguer uma espécie de barricada que impede a entrada da realidade de fora, representada por um mendigo usuário de crack. O diálogo da consumidora obsessiva com um vestido vermelho, a manequim defeituosa à procura do emprego inacessível, o entregador de mercadorias que se masturba nas mulheres de gesso, a costureira boliviana entrevada em sua máquina, a noiva vestida para um casamento que nunca virá são alegorias desse mundo de consumo, que cristalizam o fetiche associado ao sistema da moda. E revelam, desde o início do percurso, o interesse da encenação em roteirizar o espaço do shopping para desconstruí-lo.

pela cidade estimulariam reinterpretações do espaço com base na experiência vivida. No mesmo documento, Guy Débord considera "a construção de situações" como o princípio de destruição da moderna noção de espetáculo", que relaciona à não intervenção crítica e à manutenção da alienação. Ver a respeito Guy Débord, 2007, p. 56. 
O diretor apresenta os protagonistas dessa cadeia de atividades informais por meio de aparições fugazes, sem densidade nem continuidade dramática, criando zonas incertas de performatividade. Cenas breves, episódicas, semelhantes a workshops improvisados, parecem indicar, espacialmente, a precariedade do trabalho e o emprego informal à beira da dissolução. O procedimento fica mais evidente quando se contrapõe a imagem das oficinas clandestinas das costureiras bolivianas, pobres, feias, pouco iluminadas, à beleza pasteurizada das vitrines comerciais. A incisão crítica expõe um estado de coisas referido à vida contemporânea que se estende por toda a cadeia de produção e consumo" (Xavier, 2012).

A "arqueologia da memória" indica a direção da caminhada após a saída do shopping rumo ao Teatro de Arte Israelita Brasileiro (TAIB), emblema de outro tempo. Entre um polo e outro, altera-se a forma de composição da dramaturgia espacial. Na rua, a cena se constitui a partir de um conflito de ocupações e desocupações do espaço, na tensão que envolve o movimento do teatro e a realidade do bairro com seu fluxo de passantes e veículos. As duas vias se contaminam e se potencializam para que a fronteira entre real e ficcional permaneça instável.

Os pontos de maior de voltagem dessa convivência tensa são um desfile de modas na esquina da rua José Paulino e uma luta entre mulheres nuas num ringue improvisado no meio da via pública. Nessas estações, a cena se afirma com uma intensidade que contrasta com a realidade dos ônibus e seus passageiros, dos transeuntes perplexos, dos carros que buzinam para desobstruir o trânsito.

É dolorosa e incômoda a ocupação do TAIB, que no passado foi palco de resistência à ditadura militar. O abandono do lugar, as poltronas deterioradas, o piso gasto e escurecido, o cheiro de mofo e a penumbra asfixiantes são quebrados, momentaneamente, pela dança dos viciados em crack que os atores executam no palco. Em sua longa trajetória, é a primeira vez que o Teatro da Vertigem ocupa um palco italiano. Num espasmo de agitação, música e luz reaviva a cena por poucos minutos antes que os espectadores sejam retirados por contra-regras-funcionários de higienização. Já na rua, acontece a despedida impactante, com as mulheres-manequim descartadas na caçamba de entulho, sinalizando o fim de linha da cadeia produtiva e o desenlace da dramaturgia performativa de Bom Retiro 958 metros. 
Sem dúvida, a imersão radical do espectador no experimento da cidade é o traço diferencial do trabalho. E o mais importante é que dá continuidade ao movimento de deriva que orientou o processo de criação, e permanece na travessia processual de atores e espectadores pelo bairro do Bom Retiro. Na via desse percurso e dessa prática relacional é evidente a revelação de indícios da criação. A impressão que se tem é que não é possível separar o espetáculo, supostamente acabado, do processo que nele permanece como resíduo. Na zona de performatividade acionada pelo dispositivo de deriva e acentuada no deslocamento e no deslizamento de um território a outro, o que se cria é a circulação contínua de funções entre criadores, observadores e experimentadores. Nesse sentido, pode-se especular sobre a nova função do espectador, que se torna testemunha privilegiada de uma espécie de dossiê genético em ação, documento vivo de uma cena que registra seu processo inacabado de feitura.

\section{Referências bibliográficas}

AGAMBEN, Giorgio. Signatura rerum. Sur la méthode. Paris: Librairie Philosophique J. Vrin, 2008.

BERNARDET, Jean-Claude. O processo como obra. Folha de S. Paulo - Caderno Mais!, 13 de julho de 2003.

BOROWSKI, Mateusz e SUGIERA, Malgorzata. (Org.) Fictional realities/real fictions. Newcastle: Cambridge Scholars Publishing, 2007.

FÉRAL, Josette. Theatricality: on the specificity of theatrical language, Substance, Wisconsin, n. 2, p. 3-12, 2002.

FÉRAL, Josette. Performance et théâtralité, le sujet desmistifié. In: Théâtralité, écriture et mise en scène. Québec: Ed.Hurtubise, 1985, p.125-140.

FÉRAL, Josette. Théorie et pratique du théâtre. Au-delà des limites. Montpellier: Éditions I'Entretemps, 2011.

FISCHER-LICHTE, Erika. Réalité et fiction dans le théâtre contemporain. Revue d'Études Théâtrales. Registres. Paris, n.11/12, p. 7-22, 2007.

FISCHER-LICHTE, Érika. The transformative power of performance, New York: Routledge, 2008.

GRÉSILLON, Almuth, MERVANT-ROUX, Marie-Madeleine, BUDOR, Dominique. (Org.) Genèses théâtrales. Paris: CNRS, 2010.

LEHMANN, Hans-Thies. Teatro pós-dramático. São Paulo: Cosac Naify, 2007.

RANCIÈRE, Jacques. A partilha do sensível: estética e política. São Paulo: Ed. 34, 2005.

SAISON, Maryvonne. Les théâtres du réel. Paris: L'Harmatan, 1998.

SCHECHNER, Richard. Performance Studies. An introduction. New York and London: Routledege, 2006. 